\title{
Envisioning and Writing a Thesis Proposal
}

\author{
By Peter J.S. Franks
}

ENVISIONING AND WRITING a thesis proposal is one of the most difficult things a student does in graduate school. Students typically have no experience in writing proposals-or even in conceiving of thesis-sized research programs. Nor should they-they are doing graduate work to develop these skills. Often a student is left to write a thesis proposal with almost no guidance about the purpose of the proposal, its content and organizational structure, or how it will be judged.

After earning two graduate degrees of my own, and mentoring and advising hundreds of MS and $\mathrm{PhD}$ students in a very large department for almost three decades, I have formed some strong opinions about the thesis proposal: its purpose, structure, length, and how it should be evaluated. And, in particular, I've been frustrated at the lack of mentoring many students receive while struggling through this important process.

In my department-Scripps Institution of Oceanography at the University of California San Diego (UCSD) - there is no formal standard for what a thesis proposal looks like, and there has never been (to my knowledge) any formal discussion of a standard. Indeed, at least one faculty member did not even realize that a proposal is a necessary part of a student's progress through earning a graduate degree. (That professor's student's qualifying exam did not go well.) In my experience, students seldom receive mentoring from their advisors while writing their thesis proposals. Some faculty seem to feel that helping a student with the thesis proposal would be a conflict of interest-they don't even review drafts of the proposal. To me, this seems like an abdication of responsibility and a missed opportunity for formative mentoring: who are students supposed to learn from? Given that developing a thesis proposal is one of the most critical periods during graduate school, it should be embraced by faculty as an opportunity for guidance, mentoring, and advising.

My observations about a lack of mentoring bothered me enough that I finally began teaching a graduate course in writing a thesis proposal. Over the years, I have taught over 100 first-, second-, and third-year MS and PhD students. We would meet for two hours a week, over a 10-week quarter, to build students' understanding of how to conceive, organize, and write a proposal. Importantly, the class also provided time for the students to actually work on their proposals.

Here, I lay out some of the lessons I have learned about developing a thesis proposal. I'll begin with some questions I ask of the students to try to help them understand what they are undertaking, and why. I'll then offer my opinions on how a proposal might be structured, and the purposes of different parts of the proposal. I'll end with a short discussion of thesis committees and the student's thesis-proposal defense. My comments are addressed to both students and advisors alike, and I hope both might find something useful here. I recognize that my opinions may not be shared by all my colleagues, and that's fine. But perhaps this article can serve as a vehicle to stimulate discussion between students and their advisors, or even among faculty within departments.

\section{WHAT IS A THESIS PROPOSAL?}

In my course, my first question to the students is What is a thesis proposal? The answers I get vary greatly, and often reveal lack of insight (and mentoring) regarding this important part of earning a graduate degree.

Through the ensuing discussion, the students usually conclude that a thesis proposal is a presentation of the research the student plans to conduct for the intended degree, the knowledge gap it will fill, the questions and hypotheses motivating the research, the methods to be used, the results anticipated, and the significance and novelty of the proposed work in the context of present-day understanding of the scientific discipline. Clearly, this is a fruitful area for ongoing student-advisor conversations.

\section{WHAT IS THE PURPOSE OF A THESIS PROPOSAL?}

The next question I ask is What is the purpose of a thesis proposal? This question elicits a wider range of responses that generally fall within the categories of "to communicate your research plan," and "to secure funding and resources to accomplish your scientific objectives."

While these are both accurate, they 
both miss what I believe to be a particularly important reason for writing a thesis proposal: to develop the ability to focus one's ideas into a pragmatic research plan and then to clearly, succinctly, and persuasively communicate that plan for evaluation and feedback. Writing does not come naturally or easily to most people; writing is an acquired skill that requires practice and honing. Good persuasive, academic writing - and proposals should be persuasive-arises from well-informed, logical, analytical thinking. Crafting of the thesis proposal provides an excellent opportunity for the advisor to mentor the student to develop effective writing skills and habits.

The analysis, thinking, focusing, and communication of ideas and material for a thesis proposal is excellent training for subsequent steps in the degree program (e.g., fellowship applications, proposals to funding agencies, scientific papers, scientific talks, outreach), and for careers after graduation.

\section{HOW WILL YOUR PROPOSAL BE EVALUATED?}

The quality of a thesis proposal is (or should be) assessed using evaluation criteria-a set of standards used by proposal reviewers. To write a compelling proposal, the student must keep in mind the interests and perspectives of the reviewersmembers of the thesis committee-and the evaluation criteria, which, unfortunately, are often not explicitly stated.

When I have asked my students what they think their proposals are being evaluated on, I have heard answers such as "clear communication of your ideas," "the novelty and feasibility of your ideas or plan," "your knowledge of the literature," "your articulation and justification of a knowledge gap," and fundamentally, "your ability to complete a graduate degree." All of these answers are accurate, and many are aligned with the evaluation criteria for major funding agencies.

My students and I have found it useful to consider the "Heilmeier Catechism" created by former director of the Defense
Advanced Research Projects Agency George H. Heilmeier (https://www.darpa. mil/work-with-us/heilmeier-catechism). To help evaluate whether a risk was worth taking for his agency (or, in this context, whether a research plan is worth pursuing), Heilmeier asked:

- What are you trying to do? Articulate your objectives using absolutely no jargon.

- How is it done today, and what are the limits of current practice?

- What is new in your approach and why do you think it will be successful?

- Who cares? If you are successful, what difference will it make?

- What are the risks?

- How much will it cost?

- How long will it take?

- What are the mid-term and final "exams" to check for success?

With some tweaking, these questions form a useful guide for conceptualizing, structuring, and writing a proposal, as well as for evaluating a proposal. Committee members look for a welljustified and well-supported motivation for the research, a clear description of the proposed approach, evidence for the likelihood of success (e.g., preliminary data), and a timeline of work, with anticipated milestones.

\section{THE PROPOSAL}

My philosophy is this: if the student is going to write a thesis proposal, and the proposed science is of high quality (as it always should be), then why not write the proposal with the potential of its actually being submitted to a funding agency?

With this real-world viewpoint in mind, I have my students find the main funding agencies for their lab, download the proposal preparation instructions and review criteria for those agencies, and read them over (e.g., Falk-Krzesinski and Tobin, 2015). While there will be components of the instructions that are irrelevant for a thesis proposal, many of the instructions for content and structure, as well as the review criteria, will provide useful guidance. For example, the US National Science Foundation proposals have a 15-page limit (not including references); I find that to be a good target length for a thesis proposal. Agencies often include instructions for specific sections of the proposal, and it is good to think about following them, when they are relevant and appropriate.

Thesis proposals serve a slightly different purpose than proposals to funding agencies. They are typically focused on the research of one individual (the student); they thus describe a scientific study that will necessarily be smaller in scope than, say, a collaborative proposal from a team of scientists. They are not typically written to include a separate section concerning the societal impacts of the proposed research (though this is up to the advisor), and they are not usually requesting and justifying a budgetthough the proposed work must be feasible, given available resources.

\section{Approaching the Writing}

Writing a thesis proposal can feel utterly daunting to a student. To make it more tractable, I work with students to break it up into manageable sections. We start with a target length-say, 15 pages of text. I typically have my students generate an outline-an organizational blueprintthat includes separate sections describing the work proposed for each potential chapter of the thesis. At my institution, a thesis typically includes chapters that can form at least three publishable papers; these correspond to the chapter sections in the thesis proposal. If we're aiming for three chapters, then each section of the proposal will be about four pages, yielding 12 pages, collectively. That leaves three pages for the Introduction, Background, and Tools/Methods material that is relevant to all the chapters. For a student to write four pages on a topic on which they have already worked for a year or two is far less daunting than the prospect of writing a 15-page thesis proposal. Manageable chunks make for less stress and more efficient progress. 


\section{Getting Started}

The Here I Propose to... Statement

I always ask my class to tell me what they think is the most important part of a thesis (or any) proposal. The answers typically range from "good preliminary data" to "the questions." But what they almost invariably miss is what I believe to be the most important part of the proposal: the proposal! It's amazing how many proposals I review that have no proposal in them. Often, I will scan the whole document just looking for the word "propose" or "proposal"-and it's not there.

Therefore, an early exercise I have my students do is to write a Here I propose to... sentence. If a proposal were a murdermystery novel, this sentence would give away the murderer and the motivation for the act, possibly ruining the rest of the book. But a proposal is not a novel. The Here I propose to... sentence tells readers what they should expect as they read the rest of the document. It gives them the context and structure for the proposal. It gets them engaged with, and invested in, the ideas that follow.
I like to see the Here I propose to... sentence in bold font, somewhere on the first page of the proposal, so that it immediately catches the reader's eye. The sentence will typically come at the end of a few paragraphs that introduce the overall proposal: the subject, the issues, what we know, and finally-just before the Here I propose to... sentence-what we don't know: the knowledge gap. The Here I propose to... sentence then fills this knowledge gap with the proposed work. This proposed work, in a broad sense, has now been motivated and justified by the preceding text.

There is a potential danger of including too much material before the Here I propose to... sentence. Students may be tempted to demonstrate the breadth and depth of their knowledge in the introductory paragraphs. This should be resisted; students should strive to distill their vast knowledge of the field down to pithy, relevant, essential elements whose sole purpose is to motivate, support, and justify the Here I propose to... sentence-and the proposal itself. Again, it is import- ant to get the Here I propose to... sentence onto the first page, where readers will see it immediately.

\section{The Title}

Once we have the Here I propose to... sentence in good shape, I have each student come up with a thesis proposal title. This is a useful exercise to further conceptualize and encapsulate the essence and scope of the proposed work. The title must be short enough to fit on the spine of the printed thesis (assuming we even print theses anymore); it should be specific enough to convey the subject matter of the proposed thesis, but general enough to engage readers without miring them in potentially unnecessary specifics, such as where the work is done or what instruments are used to collect data. And my students are well aware of my tendency to include a colon in the title. The colon typically separates some very general (and hopefully engaging) words (e.g., "Plankton Patchiness") from more specific terms (e.g., "The Effects of Swimming" or "Analyses of Fronts in the California Current").

\section{EXAMPLE. USING HERE I PROPOSE TO..}

\section{Nonlinear Pasta Dynamics: Developing an Optimal Pasta-Sauce Interaction Framework By P. Maker}

Pasta, typically made from ground grains combined with water and eggs, has arisen independently in cuisines around the globe (Fusilli et al., 1973). Indeed, many national cuisines are centered around pasta dishes (Yi Mein and Penne, 2002). As these cuisines evolved, particular pasta shapes became associated with particular sauces: long, slender shapes with lighter seafood or cream-based sauces; long ribbons with rich, meaty sauces; concave shell shapes with rich cream or meat sauces; twisted shapes with light, smooth sauces; hollow tubes with heavy vegetable sauces or baked cheese dishes; and smaller pastas with soups, stews, and salads (Gemelli et al., 2012). Rigate et al. (1957) argued that the particular associations of pasta shapes and sauces were evolutionary optimizations of pasta surface area to volume ratios vs. sauce viscosity. More recently, Mostaccioli et al. (2018) showed a strong relationship between pasta rugosity and the granularity of the optimal sauce. Both of these hypotheses rely on untested assumptions regarding the micron-scale, multi-phase interactions of pastas and sauces. The recent invention of the Pastificator-a tool for quantifying micron-scale pasta-sauce interactions-provides a novel opportunity to test and potentially reconcile prevailing pasta-sauce-optimization hypotheses. Here I propose to develop a unifying pasta-sauce optimization framework, based on micron-scale measurements from the Pastificator, applied to a broad array of pasta/sauce combinations. This framework will improve our understanding of the origins of historical pasta-sauce combinations, and provide a basis for future pasta-sauce developments. 
Coming up with a thesis title forces students to focus their thinking. A thesis, writ large, can be overwhelming-a giant thing that the student has to do for the next half decade or so. Formulating a thesis title is a step toward reducing the vast scope of everything that one might do down to something finite and tractable. I'll add that I do this same exercise with students who are writing papers; the title will often help to focus the paper and the student's perception of its content, story, and structure.

These two exercises-the Here I propose to... sentence and the thesis proposal title-are designed to get the creative juices flowing. They help to lay a scientific foundation for the writing of the rest of the thesis proposal, providing both the student and subsequent readers the underpinnings of the upcoming proposed research.

\section{Parts of the Proposal}

The Introduction

This is the first text that readers will see. It must draw them in and engage them in the student's vision for the research. The purpose of the Introduction is to lay out the basic information that justifies the proposal. It can also be used to state the overarching goals or more detailed objectives of the work. In some ways, the Introduction serves as an extended abstract of the proposal. It must engage, educate, and inspire the reader-and it must include a proposal!

The Introduction will begin with the paragraphs leading up to the Here I propose to... sentence. It could end there, or expand further on the statements made in those paragraphs, providing more detailed references and analysis of the literature to support the proposal (though much of that will be covered in the Background). Having read the Introduction, the reader should have a good sense of what the student wants to do, why, and how it might be done (in very general terms). The student should have identified the knowledge gap and shown how the proposed research will fill it.

\section{Goals/Objectives/Questions}

I often recommend that the student include a short section outlining the overarching goals, objectives, or questions for the whole proposal. These should follow logically from the Introduction, and should presage the structure of the rest of the proposal. Often this section will contain one goal or question motivating each chapter. They may be quite general and are typically in a bulleted or numbered list. More detailed questions or hypotheses will appear in the individual chapters.

\section{Background}

The Background section is used to put meat on the bones of the Introduction and flesh out the basis for the Goals/ Objectives/Questions. It will usually contain a succinct, focused review of the literature to support the statements and contentions laid out in the Introduction. Its purpose is to further develop and justify the case for the proposed research, in the context of the literature and present knowledge or practice.

\section{Literature Review or}

\section{LITERATURE REVIEW?}

The purpose of the literature review is to identify and support the existence of a knowledge gap, providing context for the proposed work. It should be honed and focused to serve that specific purpose. It can be a separate section, or folded into the Introduction or Background.

Some of my colleagues require the Background to include an extensive literature review on the student's topicwhich may run to more than 50 pages of text! I don't follow this practice. I've found that thesis committee members rarely read the document carefully, and, until the student is fairly far along in their research, it is entirely possible that the literature review will focus on material that is ultimately only peripherally related to the subsequent research. Certainly, my own $\mathrm{PhD}$ thesis turned out to be on an entirely different mechanism than the one I had proposed to study (as it turned out, the proposed mechanism did not occur in my study area).

Once the student is well into thesis research, a synthetic, analytical literature review can be an excellent addition to the thesis itself; many of my students have published thoughtful review papers that appeared as introductory chapters of their theses.

\section{Tools/Methods}

If some or all the proposed work will be based on particular methods or tools, I suggest that they be introduced after the Background, but before the Proposed Research. This section will inform readers about the methods common to all the chapters, and give them a sense of how the student will do the work that was proposed in the Introduction and fleshed out in the Background. Putting these Tools/Methods together in one section saves repeating them in the chapterfocused sections of the Proposed Research, shortening the proposal, and reducing redundancy.

This section is often divided into subsections describing each individual tool or method. If the student's research involves developing a new tool or method, then that should be described in the appropriate chapter subsection of the Proposed Research.

\section{Proposed Research}

This section is the meat of the proposal. I recommend dividing the Proposed Research section into subsections-one for each proposed chapter of the thesis. Each chapter subsection thus becomes a sub-proposal within the larger structure of the overarching thesis proposal.

For each chapter subsection I recommend organizing it as:

- Title

- Introduction to this chapter's research focus (including literature citations, as appropriate-usually 1-2 pages of text and figures

- Statement of the specific questions, goals, objectives, or hypotheses of this chapter-a paragraph, often with a bulleted or numbered list 
- Preliminary Results - usually 2-3 pages of text (sometimes more, depending on how much previous research has been done) that include figures and tables as appropriate

- Discussion of the preliminary resultsusually a page or so of text

- Next Steps - a few paragraphs

- Significance - a paragraph

Typically, the Chapter 1 section of the Proposed Research will be far more fleshed out and have more preliminary results than subsequent chapters. But this is an excellent opportunity for students to demonstrate what has already been accomplished, their ability to pose good questions and to design appropriate experiments and analyses, and their skill at drawing robust conclusions from their analyses. As the student writes these chapter sections, the Heilmeier Catechism should be kept in mind, and the writing should focus on the very narrow scope of the research proposed in this chapter.

Many students include a list of null and alternate hypotheses to guide the research in each chapter. My experience is that these are often quite naive, and are soon replaced with better-defined hypotheses as the work progresses. I have also observed that graduate students often do time I read it, when I was well into my study, it was transformative, fundamentally improving the quality of my science. Timing is everything.

Organizing the Proposed Research by chapter can work well for students whose proposed research does not fall easily into a single subject area. Many of the students I interact with develop new instruments; their proposals thus have chapters on the instrument itself (and its calibration, etc.), and subsequent chapters on the deployment and scientific application of the instrument. The thesis proposal thus provides an umbrella for combining these potentially very different types of research.

After having read a chapter section, a thesis committee member should have a clear sense of what the student proposes, why it is important, what has already been done, what will be done, and how it will be done.

\section{Summary/Broader Impacts}

A brief summary of the student's proposed work can bring the disparate threads of the various chapters together at the end of the proposal. It will be the last piece of text that readers will see, and provides a final opportunity to hammer home the important points.

\section{Envisioning and writing a thesis proposal}

\section{is one of the most difficult things a student does}

\section{in graduate school.}

not really understand how to formulate testable hypotheses-and perhaps more importantly-alternate hypotheses. This usually improves with experience and mentoring. One of the best papers I have encountered on this subject is "Strong Inference" (Platt, 1964). It was certainly powerfully influential for me. The first time I read it (early in graduate school), I got very little from it. But the second
Though not always necessary for a thesis proposal, many funding agencies require an explicit statement about the potential societal benefits of the proposed work (e.g., NSF's "Broader Impacts"). One of my own committee members told me that he would ask only one question at my thesis defense: "Who cares?" (And he did.) While I don't think I'm particularly good at answering that question, it is always at the front of my mind. I think it is a very healthy activity for students to ponder why they are doing what they are doing, and what its relevance might be for the discipline or for society.

\section{Timeline}

My students often include timeline tables as the last pages of their thesis proposals. The rows of the timeline are specific tasks articulated in the proposal, such as developing and applying models or techniques, acquiring data, analyzing data, writing papers, and submitting papers. The columns are dates from the present up to the proposed graduation date. These timelines are always ambitious, and often unachievable-I never hold my students to the timeline. Never having done it before, it's not possible to have an accurate view of how long something will take. And everyone always forgets to factor in the unexpected, such as injuries and illnesses, equipment failures, family emergencies, and changes in access to resources. My general rule of thumb is to take the student's expectation of how long something will take... and multiply by five to get a more realistic timeline.

\section{WORKING WITH YOUR ADVISOR AND THESIS COMMITTEE}

In my department, forming a thesis committee begins well before writing the proposal, with discussions between the student and advisor about appropriate potential members. There are many considerations, including areas of expertise, seniority, participation in group projects, access to infrastructure and instrumentation, likelihood of useful participation, and intangibles such as personality. I encourage my students to find people whose expertise will complement and supplement mine, and who are likely to contribute in positive ways to their success. It is good to be mindful of all aspects of diversity when forming a committee: gender, culture, heritage, discipline, etc. And it is often good to have someone on the committee who does not always agree with everyone else. 
My student and I usually come up with a list of more potential committee members than are needed. The student then contacts those on the list and meets with them to give them an outline of the proposed research (though this is usually well before a thesis proposal has been written). My student and I then meet to discuss the results of these interactions; occasionally there's an obvious mismatch of personalities or approaches, and we take that person off the list. The final thesis committee must then be formally approved by our university's graduate division.

The thesis proposal is then written to this audience. But when should the committee see the proposal? Should the sausage-making be shared, or only the final product?

Other than the advisor, committee members are not typically involved in the writing and revising of the proposal, though I would definitely recommend that students take them up on any offers of help or mentoring during this process. Unfortunately, many committee members will be too busy to make this kind of time available to students who are not their own. Typically, a student should get the final proposal to committee members two weeks before the proposal defense (the "qualifying exam" in our department). That being said, I think it is a great idea for the student to meet with each faculty member individually a month or more prior to the exam to go over the ideas in the thesis proposal. This meeting helps to get everyone on the same page, and alert the student to any potential problems raised by committee members.

\section{DEFENDING YOUR}

\section{THESIS PROPOSAL}

Different departments have different procedures for examining student thesis proposals. For my department's qualifying exams, the students prepare 40-50 minute (or so) presentations of their proposed work (typically based on the structure of the thesis proposal). The thesis committees usually ask questions about the proposed work during the presentations, with follow-up questions afterward; most of the exams I attend take two to twoand-a-half hours. It's possible they would go faster if I weren't there; I tend to ask a lot of questions.

The purpose of the exam is to ensure that a student has articulated a feasible and relevant set of research questions and is capable of carrying out the proposed research to earn the intended degree. It is also an opportunity for the committee members to offer their help and expertise in achieving the stated goals.

It may be idiosyncratic of my department, but I emphasize to students that their committee is not there in an adversarial role. The members are there to help-to offer their expertise to assist the student in doing the best work possible. They are there as resources-intellectual, physical (e.g., equipment, space), and often emotional. They are there to supplement the expertise of the student's advisor. They are there as potential colleagues and collaborators.

When students understand the roles of the thesis committee, the proposal defense becomes less of a battle and more of an interesting and fruitful scientific conversation. If a student does not do well at the proposal defense, I have observed that it is almost always the result of poor (or no) mentoring by their advisor.

One thing that happens at almost every qualifying exam I have participated in is that committee members suggest that the proposed work is overly ambitious and unlikely to be accomplished in a reasonable time. They usually recommend that the student focus on a subset of the proposed work-to limit the scope, but perhaps to increase the depth in one area. They often suggest that what was proposed as one chapter should actually be two-or more. Sometimes these suggestions are perceived by the student as criticisms, but more often as a welcome relief.

One thing I stress to students is that the proposal is not a contract-we expect things to change. It's the nature of science. If we knew exactly how things would work out, science would be pretty boring.

\section{TO SUMMARIZE}

The very idea of a thesis proposal-or a thesis-can be overwhelming. It can appear as a huge, amorphous, stressinducing task, with no boundaries or definition. By understanding the purpose of a thesis proposal, the proposal's audience, and the proposal's evaluation criteria, the task of writing the proposal becomes tractable and manageable. Starting with seemingly small exercises such as the Here I propose to... sentence and the title helps to launch the student onto a productive trajectory. Breaking the writing and intellectual investment into manageable chunks allows for achievable, positive metrics of progress and success. And I know from experience that the students are buoyed by their demonstrated, incremental successes in writing, editing, improving, and submitting their thesis proposals.

In particular, I think it is important for advisors to recognize how overwhelmingly difficult writing_or even conceiving of $-\mathrm{a}$ thesis proposal can be for a graduate student. It offers a wonderful opportunity to forge a constructive mentoring and advising relationship with that student. It may be a particularly formative experience that can have positive reverberations in many unpredictable ways later in the student's life. @

\section{REFERENCES}

Falk-Krzesinski, H.J., and S.C. Tobin. 2015. How do I review thee? Let me count the ways: A comparison of research grant proposal review criteria across US federal funding agencies. Journal of Research Administration 46(2):79-94.

Platt, J.R. 1964. Strong inference. Science 146(3642): 347-353, https://doi.org/10.1126/science.146. 3642.347.

\section{ACKNOWLEDGMENTS}

I thank the Scripps Institution of Oceanography graduate students for insisting that I teach my "Writing a Thesis Proposal" course, and for their inspiration and feedback. Sharon Franks and Allison Cusick were particularly helpful in revising the manuscript. A special thank you to Ellen Kappel, who asked me to write this.

\section{AUTHOR}

Peter J.S. Franks (pjfranks@ucsd.edu) is Distinguished Professor, Scripps Institution of Oceanography, University of California San Diego, La Jolla, CA, USA.

\section{ARTICLE DOI}

https://doi.org/10.5670/oceanog.2021.316 